\title{
Chromatographic and Voltammetric Characterization of Chlorogenic Acids in Coffee Samples
}

\author{
Ivana Tomac, * Lidija Jakobek, Marijan Šeruga
}

\author{
Faculty of Food Technology Osijek, University of Osijek, F. Kuhača 20, HR-31000 Osijek, Croatia
}

* Corresponding author's e-mail address: itomac@ptfos.hr

RECEIVED: November 6, 2018 * REVISED: March 11, 2019 * ACCEPTED: March 12, 2019

Abstract: The accurate and precise characterization of eight chlorogenic acids (CGAs) isomers, caffeoylquinic acids (5-CQA, 4-CQA, 3-CQA), dicaffeoylquinic acids (3,5-diCQA, 4,5-diCQA, 3,4-diCQA), and feruloylquinic acids (5-FQA, 4-FQA), was carried out using different brands of coffee. High-performance liquid chromatography (HPLC), differential pulse (DPV) and square-wave voltammetry (SWV) were applied for the investigation. HPLC proved to be an accurate and precise method for separation, identification and quantification of CGAs isomers in coffee extracts. DPV and SWV have shown that electrochemical behaviour of coffee extracts was very similar to that of CGAs isomers and DPV and SWV can be used for the correct characterization of CGAs in coffee. All three techniques have shown a very high correlation of CGAs content in all investigated coffee samples. Therefore, HPLC, DPV and SWV methods can be used in combination as very selective, sensitive and precise methods for characterization of CGAs isomers in coffee extracts.

Keywords: voltammetry, HPLC, chlorogenic acids, coffee.

\section{INTRODUCTION}

OFFEA arabica and Coffea robusta from the family Rubiaceae are the most important types of coffee beans. ${ }^{[1]}$ Coffee is a worldwide popular drink, whose popularity lays in its specific taste and aroma. Green and roasted coffee beans have a complex chemical composition due to the presence of various biologically active compounds. The most abundant bioactive compounds in coffee are chlorogenic acids. Chlorogenic acids (CGAs) are polyphenol compounds, which represent esters of (-)-quinic acid and certain trans-cinnamic acids (caffeic, ferulic, and $p$-coumaric acid). A large number of recent chemical, nutritional, medical and epidemiological studies on the biological effects of coffee have been conducted. Thus, some studies showed that drinking coffee beverages in moderation has antioxidant, anti-inflammatory, the anticancer and antibacterial effect on the human body. ${ }^{[1-3]}$ Also, the coffee beverages were associated with a reduced risk of developing Alzheimer's disease, Parkinson's disease, cardiovascular diseases, liver disease, diabetes type 2 and various cancers and as well as with beneficial effects on cognitive performance and mood. ${ }^{[4]}$

High performance liquid chromatography (HPLC) method is commonly used method for the separation, identification and quantification of chlorogenic acids in coffee. In the literature, extraction of chlorogenic acids from coffee is carried out using various solvents $(40 \%$ methanol, methanol and $\mathrm{Na}_{2} \mathrm{SO}_{3}$, distilled water at $90{ }^{\circ} \mathrm{C}$ to $100{ }^{\circ} \mathrm{C}$, etc.). ${ }^{[5-8]}$ Afterwards, the CGAs content was determined by HPLC with UV/Vis or photo diode array (PDA) detector [5,8-10], using a different mobile phase ( $2 \mathrm{mM}$ phosphoric acid and methanol, $0.3 \%$ formic acid and methanol, $0.2 \%$ acetic acid and methanol, $10 \mathrm{mM}$ trisodium citrate and methanol, etc.).

In the last years, electrochemical voltammetric techniques became methods of choice for coffee analysis. The most used voltammetric method was square-wave voltammetry (SWV) with different electrochemical sensors or biosensors. ${ }^{[11-13]}$ Also, different solid electrodes were 
used for analysis. Thus, Yardim ${ }^{[14]}$, and Yardim et al. ${ }^{[15]}$ used adsorptive stripping SWV (AdTSSW) on the boron-doped diamond electrode for determination of CGAs in coffee beverages. Differential pulse voltammetry was also used for determination of CGAs content in coffee. Thus, Ziyatdinova et al. ${ }^{[16]}$ and Santos et al. ${ }^{[17]}$ applied DPV technique, using multiwall carbon nanotubes (MWCNT) as a working electrode ${ }^{[16]}$ or molecularly imprinted siloxane (MIS)/Au sensor. ${ }^{[17]}$ In the most voltammetric analyses of coffee samples total CGAs content was expressed as 5-CQA content but only in few studies other CGAs were determined. ${ }^{[18,19]}$

In the present study, the results obtained from both chromatographic and voltammetric techniques were combined. Usually, the literature comprises different terms of CGAs content expression as "total CGAs content" or "5-O-caffeoylquinic content equivalent" and does not specify the type of CGAs isomer or it only examines the 5-O-caffeoylquinic acid content. It is not easy to separate chlorogenic acids, especially feruloylquinic acids (4-FQA and 5-FQA). There is a need for an efficient separation, identification and quantification of each individual chlorogenic acids isomers (CQAs, diCQAs and FQAs) in coffee, using HPLC/PDA technique and that was one of the aims of this study. The second aim was to use the voltammetric techniques (DPV and SWV) for the characterization of CGAs isomers in the same coffee samples. The CGAs content of all investigated coffee samples obtained by HPLC/PDA method was compared to voltammetric results.

\section{EXPERIMENTAL}

\section{Chemicals}

Pure compounds used as standards were purchased as follows: chlorogenic acids; caffeoylquinic acids: 3-CQA (neochlorogenic acid, C3878, $\geq 95 \%$ ), 4-CQA (cryptochlorogenic acid, 65969, $\geq 98 \%$ ) and 5-CQA (chlorogenic acid, 94419, $\geq 98 \%$ ) from Sigma-Aldrich (St. Louis, MO, USA), dicaffeoylquinic acids: 3,5-diCQA (isochlorogenic acid A, SMB00131, $\geq 95 \%$ ), 3,4-diCQA (isochlorogenic acid B, SMB00224 $\geq 90 \%$ ) and 4,5-diCQA (isochlorogenic acid C, SMB00221, $\geq 85 \%$ ) from Chengdu Biopurity Phytochemicals Ltd. (Chengdu Sichuan, China). Methanol (HPLC grade) was purchased from Merck (Darmstadt, Germany) and ortho-phosphoric acid ( $85 \%$, HPLC grade) from Fluka (Buchs, Switzerland). Sodium dihydrogen phosphate and disodium hydrogen phosphate were obtained from Kemika (Zagreb, Croatia). Alumina powder was obtained from Buehler (USA). Feruloylquinic acids (4-FQA, 5-FQA; $\geq 98 \%$ ) were donated from I. Dokli and Z. Hameršak from Ruđer Bošković Institute (Zagreb, Croatia) who synthesized these three isomers, characterized and confirmed their structure. ${ }^{[21]}$

\section{Standard Solutions}

Stock solutions of all CGAs were prepared in methanol, HPLC grade, and stored at $4{ }^{\circ} \mathrm{C}$. Working solutions were prepared by dilatation of an appropriate volume of stock solution CGAs in methanol (HPLC grade) or in $0.1 \mathrm{~mol} \mathrm{~L}^{-1}$ phosphate buffer solution for voltammetric analysis, immediately prior to measurement.

\section{Sample Preparation}

Ten different coffee brands were analysed. Two types of green and roasted beans ( $C$. arabica and $C$. robusta), two types of ground coffee and four types of instant coffee. Ground and instant coffee samples were purchased the local market. Green beans and roasted beans were a donation from Anamarija Company, Zagreb. Green and roasted beans were milled in the manual coffee grinder, while the other types of coffee were analysed in original shape. A coffee sample was prepared according to the procedure of Delgado-Andrade et al. ${ }^{[22]} 1 \mathrm{~g}$ of the coffee sample was added to $100 \mathrm{~mL}$ of ultrapure water, heated to $80^{\circ} \mathrm{C}$, mixed for 3 minutes with magnetic stirrer and filtered through filter paper prior to the analysis. When coffee samples were cooled down to room temperature, they were filtered through a PTFE filter, pore size $0.45 \mu \mathrm{m}$ (VariSep PTFE, $0,45 \mu \mathrm{m}, 25 \mathrm{~mm}$, Varian).

\section{High-Performance Liquid Chromatography}

The separation, identification and quantification of chlorogenic acids in the investigated coffee samples were performed using the HPLC method.The HPLC analysis was carried out using the Varian instrument (USA) consisting of Prostar 230 pumpsand ProStar 330 PDA detector. The separation of chlorogenic acids from the coffee samples was performed by using a column of C18 OmniSphere (internal diameter $250 \times 4.6 \mathrm{~mm}$, particle diameter $5 \mu \mathrm{m}$, Varian, USA) with a protected column (ChromSep $1 \mathrm{~cm} \times 3 \mathrm{~mm}$, Varian, USA). Data was recorded and processed by using the Star Chromatography Workstation Software (version 5.52). Chlorogenic acids were separated by the reversedphase high-performance liquid chromatography (RP-HPLC) using two mobile phases: $0.1 \%$ phosphoric acid (A) and $100 \%$ methanol (B). The gradient was as follows: 0 min $5 \%$ B, $30 \min 80 \%$ B, $33 \min 80 \%$ B and $35 \min 5 \%$, at flow rate of $0.8 \mathrm{~mL} \mathrm{~min}{ }^{-1}{ }^{[23]}$ The aqueous coffee extracts and authentic chlorogenic acids standards were injected in a volume of $10 \mu \mathrm{L}$. The period of re-equilibration time between individual measurements of coffee samples was 10 minutes and the UV spectra were recorded in the wavelength range between 200 to $600 \mathrm{~nm}$.

The identification of CGAs in coffee samples was performed by comparing retention time, chromatogram appearance of each individual standards and UV spectra. The 
coffee extracts were spiked with a known concentration of each individual standard for peak identitification UV spectra detection was carried out at a wavelength of $320 \mathrm{~nm}$, corresponding to the each individual CGAs maximum absorption.

In this study, the quantification was performed by creating a calibration line of each individual CGAs using the HPLC method. From each of ten different coffee brands three or more coffee extracts were prepared in the way described in the sample preparation and they were analysed at least three times or more. The green bean coffee extracts were diluted a hundred times and all the other coffee extracts fifty times.

Calibration line was based on HPLC chromatograms of each individual CGAs standards in the range of different concentrations, recorded at $\lambda=320 \mathrm{~nm}$. The linear range of concentration for 5-CQA was in the range $75-300 \mathrm{mg} \mathrm{L}^{-1}$, for 4-CQA was in the range $25-75 \mathrm{mg} \mathrm{L}^{-1}$, for 3-CQA in the range 1-300 $\mathrm{mg} \mathrm{L}^{-1}$ and for diCQAs were in the range 50 $100 \mathrm{mg} \mathrm{L}^{-1}$. Linearity was evaluated by constructing a calibration line using peak areas versus the mass concentration of each compound. The LOD and LOQ were calculated mathematically by the relationship between the standard deviation of the calibration line and its slope (Table 1 ).

\section{Differential Pulse and Square Wave Voltammetry}

DPV and SWV measurements were performed by the $\mu$ Autolab potentiostat/galvanostat using GPES 4.9 software (Eco Chemie, Utrecht, Netherlands). Measurements were carried out in a standard three-electrode electrochemical cell (Metrohm, Switzerland). The working electrode was glassy carbon electrode (GCE) (3 mm diameter) model MF2012 (Bioanalytical Systems, USA). The counter electrode was Pt-wire electrode and the reference electrode was an $\mathrm{Ag} / \mathrm{AgCl}\left(3 \mathrm{~mol} \mathrm{~L}^{-1} \mathrm{KCl}\right)$ : Both electrodes were purchased from Metrohm, Switzerland.

Table 1. Calibration curve parameters for analysed chlorogenic acids standards obtained by HPLC/PDA.

\begin{tabular}{|c|c|c|c|c|}
\hline $\begin{array}{l}\text { Chlorogenic } \\
\text { acid isomers }\end{array}$ & Equation & $R^{2}$ & $\begin{array}{l}\mathrm{LOD} / \\
\mathrm{mg} \mathrm{L}^{-1} \\
\end{array}$ & $\begin{array}{l}\mathrm{LOQ} / \\
\mathrm{mg} \mathrm{L}^{-1} \\
\end{array}$ \\
\hline $\begin{array}{c}\text { 5-CQA } \\
(5-F Q A, 4- \\
F Q A)^{(a)}\end{array}$ & $y=419930 x-5402080$ & 0.9996 & 6.146 & 20.489 \\
\hline 4-CQA & $y=352634 x+114665$ & 1 & - & - \\
\hline 3-CQA & $y=364066 x+1076230$ & 0.9989 & 0.186 & 0.565 \\
\hline 3,4-diCQA & $y=498511 x+3072840$ & 0.9994 & 8.770 & 26.579 \\
\hline 3,5-diCQA & $y=641842 x+2060730$ & 0.9999 & 1.366 & 4.140 \\
\hline 4,5-diCQA & $y=541480 x+9000000$ & 1 & - & - \\
\hline
\end{tabular}

The experimental conditions for DPV measurements (pulse amplitude $50 \mathrm{mV}$, pulse width $70 \mathrm{~ms}$, potential increment $2 \mathrm{mV}$, interval time $0.4 \mathrm{~s}$, scan rate of $5 \mathrm{mV} \mathrm{s}^{-1}$ ) and for SWV analysis (pulse amplitude of $50 \mathrm{mV}$, frequency of 25-150 Hz, potential increment of $2 \mathrm{mV}$, an effective scan rate of $50-300 \mathrm{mV} \mathrm{s}^{-1}$ ) were determined in our earlier studies $^{[18,19]}$

Before each measurement, the GCE was carefully polished with $0.05 \mu \mathrm{m}$ alumina slurry. Furthermore, the GC electrode was cleaned electrochemically by cycling the potential between -0.2 to $1.0 \mathrm{~V}$ at a scan rate of $50 \mathrm{mV} \mathrm{s}^{-1}$ in supporting electrolyte $\left(0.1 \mathrm{~mol} \mathrm{L^{-1 }} \mathrm{PBS}\right.$ of $\mathrm{pH}$ at which DPV and SWV measurements were done) until steady-state cyclic voltammograms were obtained. All measurements were done, at least, in triplicates, at room temperature (298 K).

In this paper, voltammograms were drawn using Origin ${ }^{\circledast} 2015$ software (OriginLab Corporation, Northampton, USA).

\section{Statistical Analysis}

The voltammetric and chromatographic results are statistically analysed by the Statistica 13.4 Software (Statsoft Inc. USA). Correlation coefficient and ANOVA (Post-hoc Tukey honest significant difference (HSD) test) were used for statistical analysis. Differences were considered significant at 0.05 level.

\section{RESULTS AND DISCUSSION}

\section{High-Performance Liquid Chromatography}

HPLC/PDA method was performed to acquire the retention times and UV-Vis spectra of each individual CGAs. This technique allowed the identification and quantification of every single standard in the coffee extracts.

In this study, eight chlorogenic acid isomers were separated and identified in all of the ten analysed coffee samples using HPLC/PDA method (Figures 1 and 2). According to the retention times, the order of elution of each individual chlorogenic acid isomers was consistent with the literature data. ${ }^{[5,24]}$ All investigated chlorogenic acid isomers in ten coffee samples were clearly separated, except 3,4-diCQA and 3,5-diCQA, wherein a common peakwas observed (peak 6 , Figures 1,2 ). The reason is that the retention times of both diCQAs were very close (the difference in retention times was 0,191 minutes) and the individual peaks were thereby connected in one common peak in all analysed coffee extracts (Figures 1, 2).

Profile of chlorogenic acid isomers in green bean coffee extracts is relatively simple (Figure 1a, 1b). Eight dominant CGAs have been found (three CQAs, three 
diCQAs, two FQAs; 5-FQA and 4-FQA), while 3 -FQA has not been identified in the investigated coffee samples. A similar HPLC profile of coffee (the presence of eight dominant CGAs, without 3-FQA) has been shown in the work of Mills et al. ${ }^{[25]}$ HPLC chromatograms of roasted coffee, ground coffee and instant coffee extracts (Figures 1c, 1d, 2) are much more complex, due to the significant changes in the chemical composition of coffee bean that occur during the roasting process of green coffee beans. ${ }^{[5,25]}$

In the literature relating to the HPLC analysis of coffee samples typically eight to nine dominant CGAs isomers were mentioned and the chromatographic profile of chlorogenic acid isomers obtained in this study is in close agreement with those found in literature. ${ }^{[5,7,24]}$

Further identification of chlorogenic acid isomers was carried out by UV/Vis spectra in the wavelength range from $200 \mathrm{~nm}$ to $600 \mathrm{~nm}$. Absorption spectra of each individual investigated chlorogenic acid isomers, as well as in coffee extracts, detected four maximum absorbance peaks between $200 \mathrm{~nm}$ to $600 \mathrm{~nm}$ (Figure 3). The first absorption peak occurs at $215 \mathrm{~nm}$, the second peak at $238 \mathrm{~nm}$ and the third at $286 \mathrm{~nm}$. The fourth absorption peak was observed at 315 $\mathrm{nm}$ for the CQAs (Figure 3a), at $316 \mathrm{~nm}$ for diCQAs (Figure $3 \mathrm{~b}$ ) and at $313 \mathrm{~nm}$ for the FQAs (Figure $3 \mathrm{c}$ ).
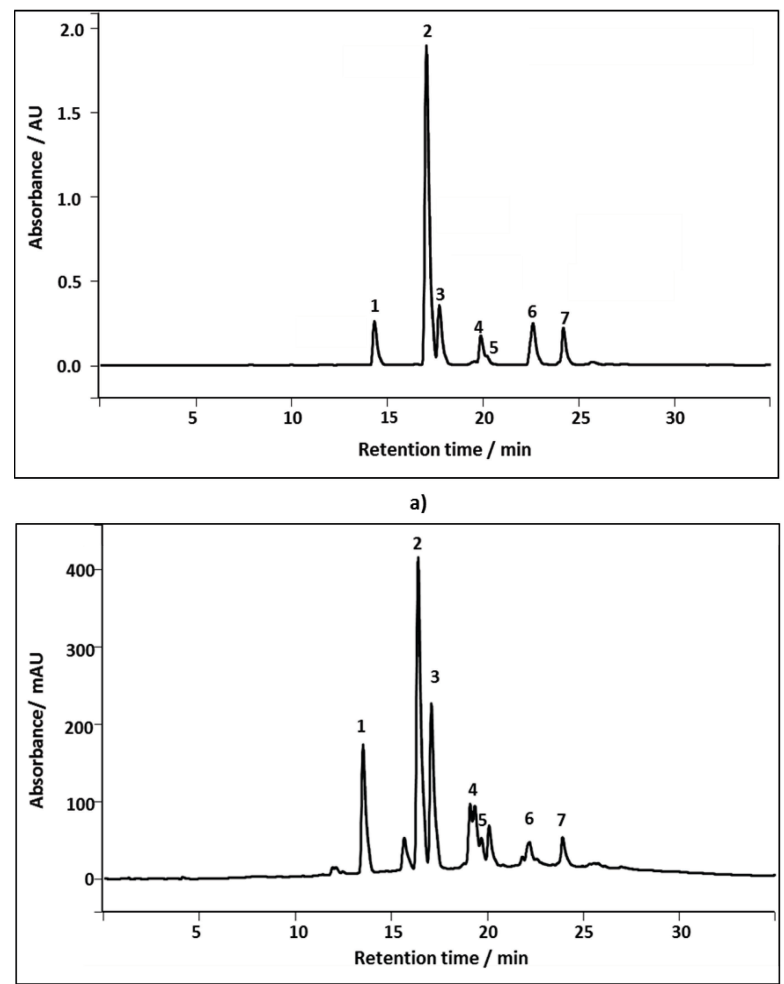

c)
Appearance and wavelength of maximum absorption peaks of coffee extracts and of each individual investigated CGAs are identical or nearly identical. This proves that all the eight isomers of CGAs are actually present in the coffee samples and their identification and quantification in coffee samples based on UV/Vis spectra are possible. ${ }^{[26]}$ In relevant literature, there is relatively little data on the UV/Vis spectra of chlorogenic acid isomers investigated in this study. Much of the data refers to research on UV/Vis spectra of 5-CQA ${ }^{[26-30]}$ while Kuhnert et al. ${ }^{[30]}$ reported data on the $\lambda_{\max }$ for more isomers of CGAs, including the ones investigated in this study. All these authors identified four absorption band peaks $\left(\lambda_{\max }\right.$ around $\left.320 \mathrm{~nm}\right){ }^{[26-30]}$ The coffee extracts were spiked with the known concentration of each individual CGAs in order to confirm peak identity. This procedure undoubtedly confirmed the identification of eight chlorogenic acid isomers in the investigated aqueous coffee extracts, due to the significant increase in absorbance peaks at retention times at which each individually added chlorogenic acid isomers were eluted (Figure 4).

The contents of each individual chlorogenic acids in the coffee extracts are shown in Table 2 . In all investigated aqueous coffee extracts the most prevalent group of CGAs
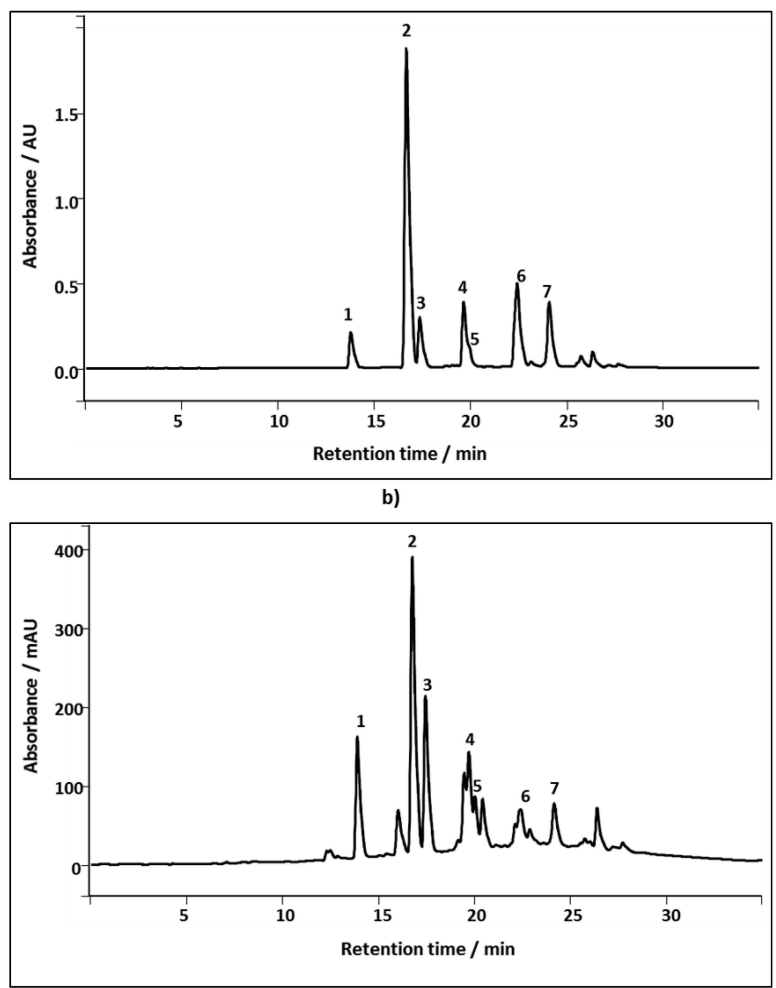

d)

Figure 1. Chromatographic profile of chlorogenic acids in a) Coffea arabica green bean, b) Coffea robusta green bean, c) Coffea arabica roasted bean and d) Coffea robusta roasted bean. $1=3-\mathrm{CQA}, 2=5-\mathrm{CQA}, 3=4-\mathrm{CQA}, 4=5-\mathrm{FQA}, 5=4-\mathrm{FQA}, 6=3,5-\mathrm{diCQA}$ and 3,4-diCQA, $7=4,5$-diCQA. 
was CQAs in the range of $60.31 \%-76.83 \%$ of total CGAs, followed by the diCQAs ranging from $13.28 \%-27.78 \%$ of the total CGAs and FQAs in the range of $6.32 \%-19.58 \%$ of total CGAs. These results are in close agreement with other authors who studied individual CGAs, like Ky et al., [6] Farah et al., ${ }^{[5]}$ Duarte et al.., ${ }^{[7]}$ Perrone et al. ${ }^{[9]}$

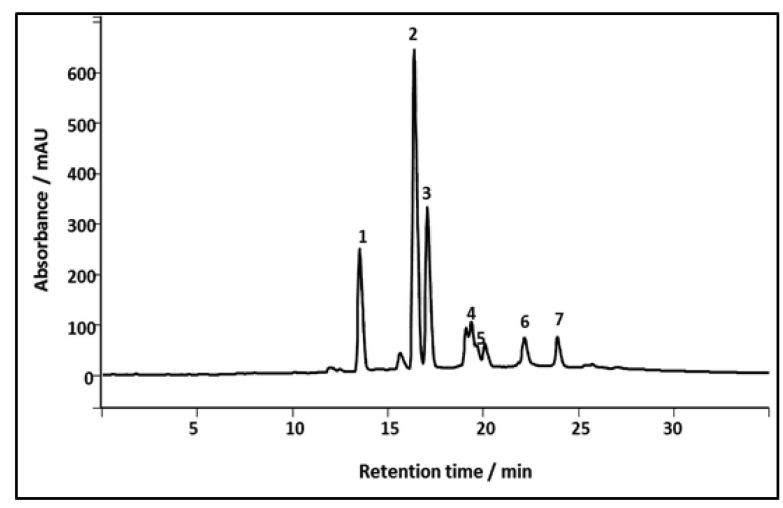

a)

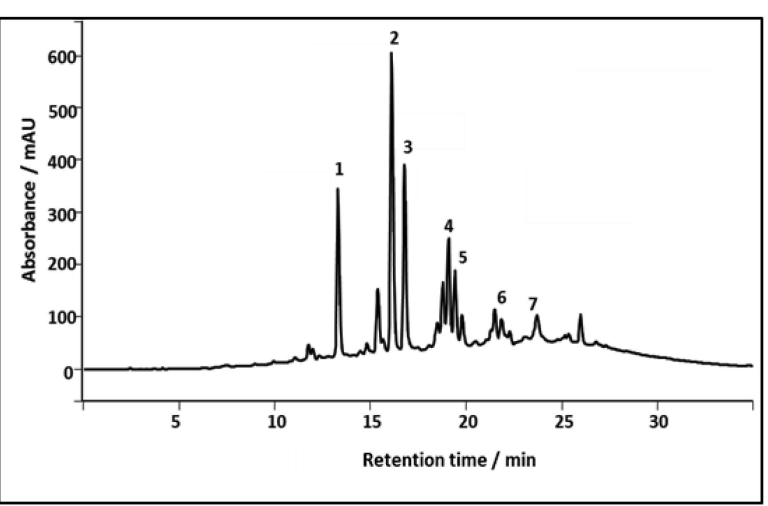

c)

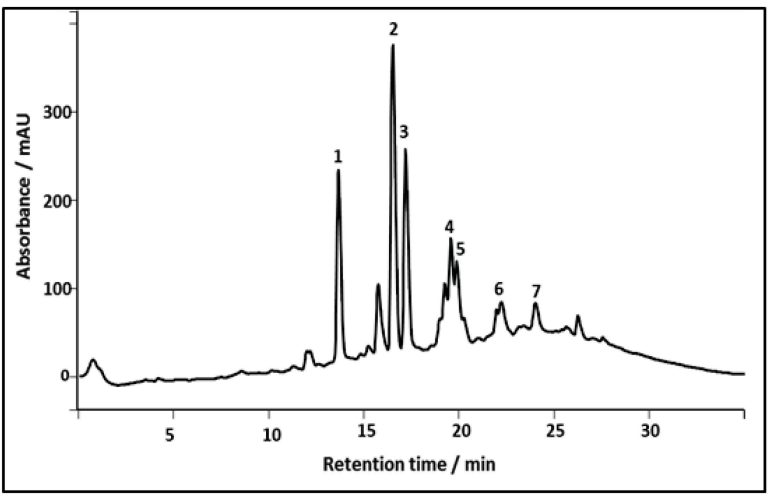

e)
Comparing the obtained results, the actual amount of each individual chlorogenic acids (taking into account the different molar extinction coefficients and different molecular weight) was calculated using the equation $C=\left(R F \varepsilon_{1} M R_{2} A\right) /\left(\varepsilon_{2} M R_{1}\right)$ ( $C$ is the concentration of the isomer in $\mathrm{g} \mathrm{L}^{-1} ; R F$ is response factor of standard in $\mathrm{g} \mathrm{L}^{-1} ; \varepsilon_{1,2}$ is

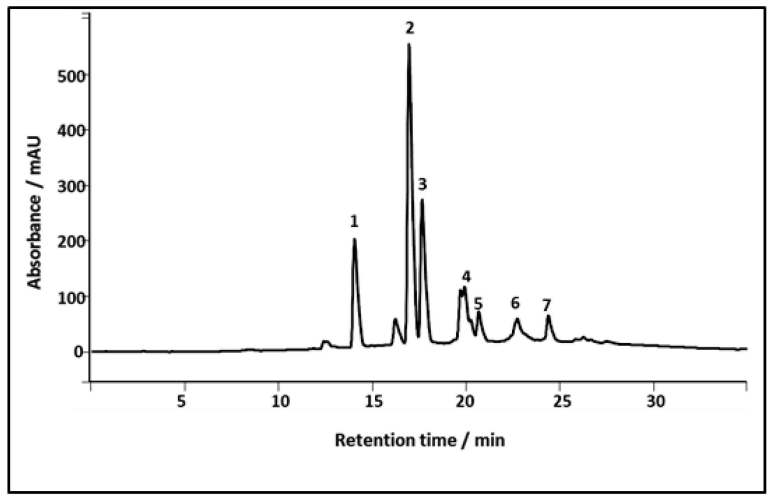

b)

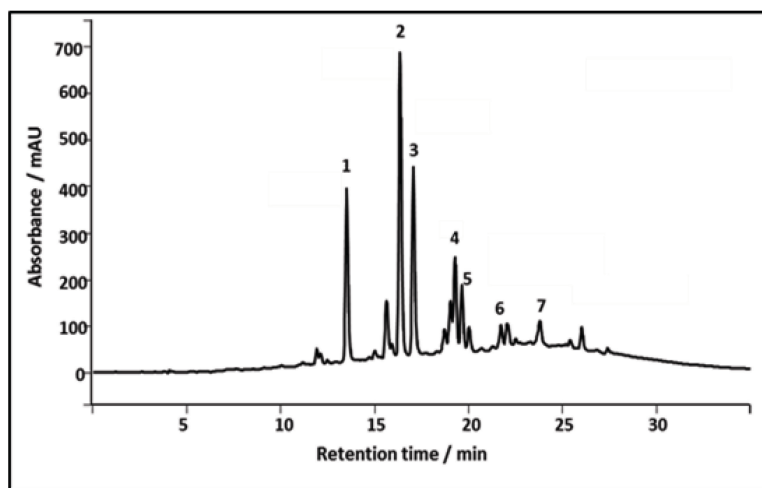

d)

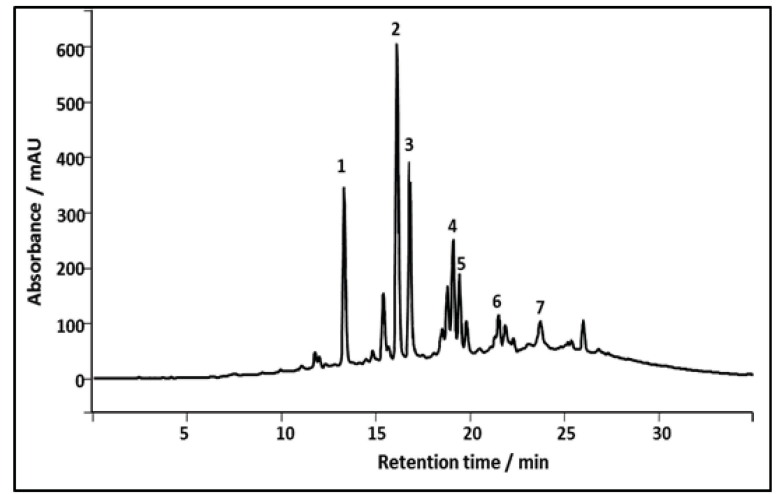

f)

Figure 2. Chromatographic profile of chlorogenic acids in a) ground coffee $1,100 \%$ minas, b) ground coffee $2,100 \%$ arabica c) instant coffee $1, d$ ) instant coffee 2 , e) instant coffee 3 and f) instant coffee $4.1=3-\mathrm{CQA}, 2=5-\mathrm{CQA}, 3=4-\mathrm{CQA}, 4=5-\mathrm{FQA}, 5=$ 4-FQA, $6=$ 3,5-diCQA and 3,4-diCQA, 7 = 4,5-diCQA. 
molar extinction coefficient of isomer; $M R_{1,2}$ is the molecular weight of isomer and $A$ is the area of the peak of the isomer) as described by Farah et al.[5] The significant difference between the different ways of calculating the amount of CGAs in the coffee extracts was not obtained. The content of each individual CGAs is significantly higher in green bean

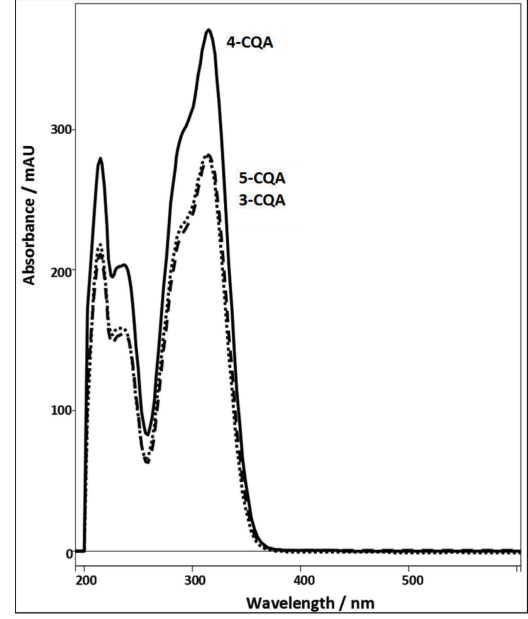

a)

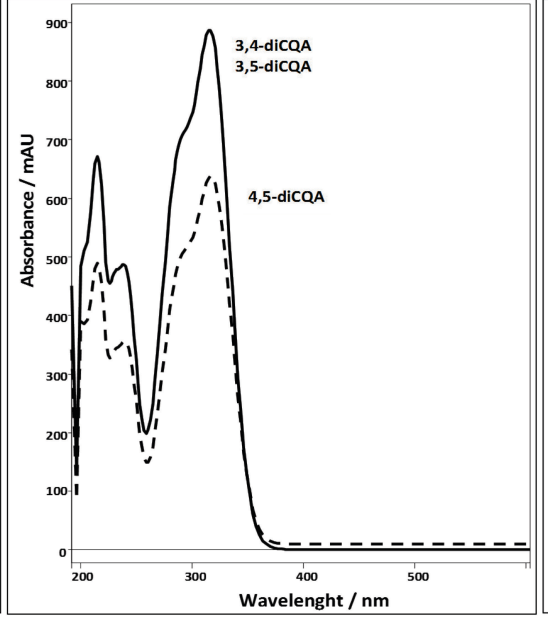

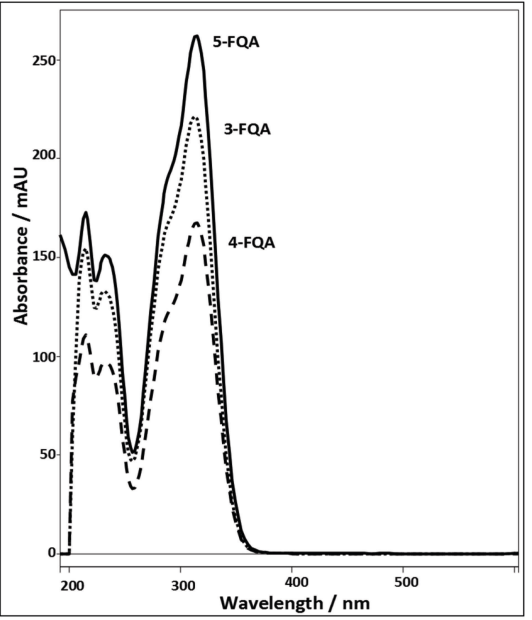

c)

Figure 3. The overlaid spectra of a) caffeoylquinic acids (CQAs), b) dicaffeoylquinic acids (diCQAs) and c) feruloylquinic acids (FQAs) in the wavelength range of $200 \mathrm{~nm}$ to $600 \mathrm{~nm}$.

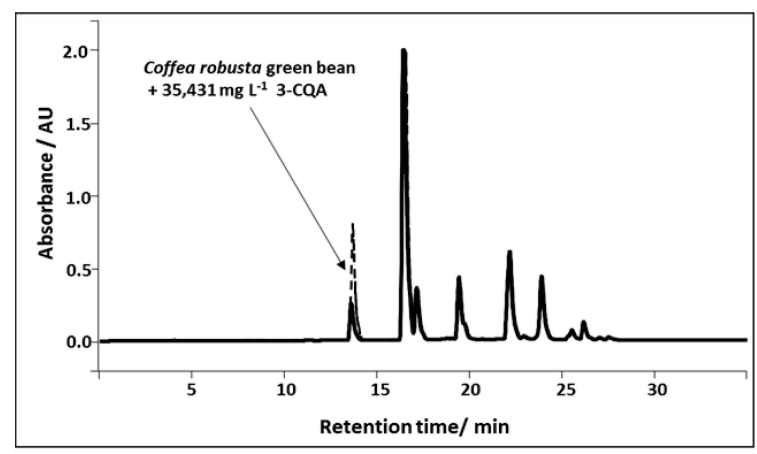

a)

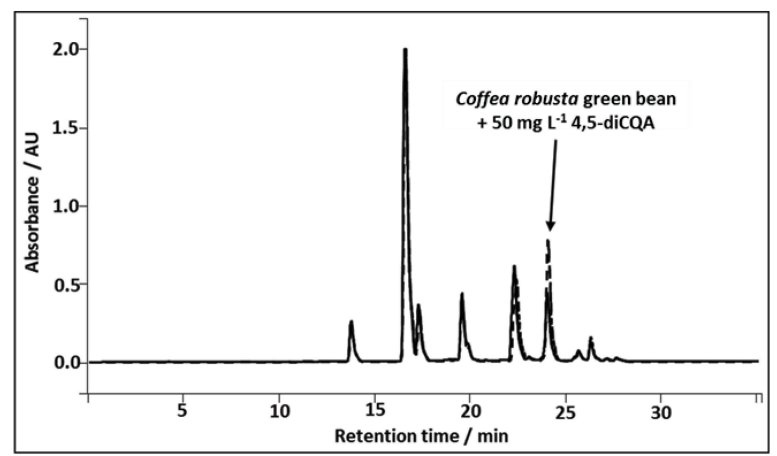

c)

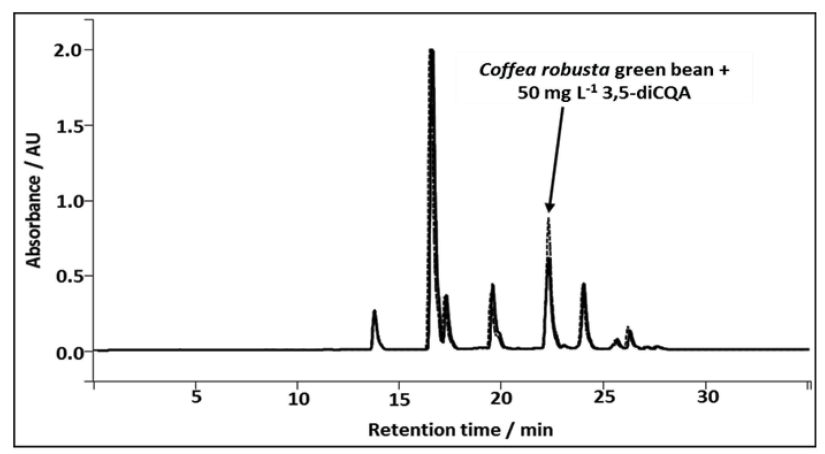

b)

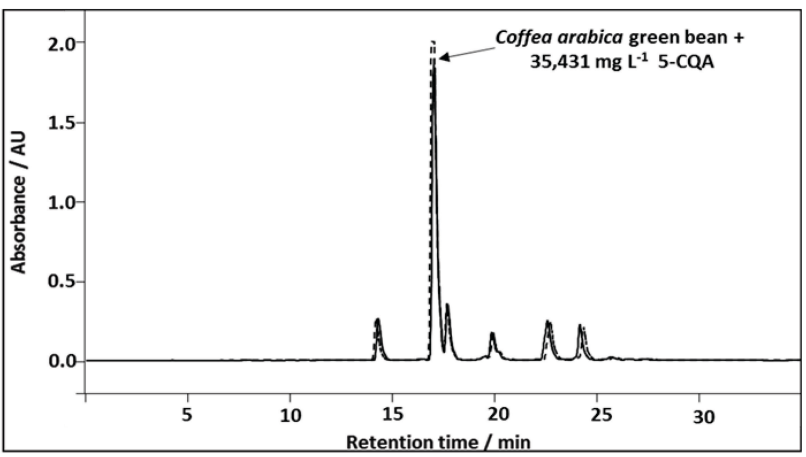

d)

Figure 4. The spiking of the Coffea robusta green bean extract for peak identity by respective standards: a) $35.431 \mathrm{mg} \mathrm{L}^{-1}$ 3-CQA, b) $50 \mathrm{mg} \mathrm{L}^{-1}$ 3,5-diCQA and c) $50 \mathrm{mg} \mathrm{L}^{-1}$ 4,5-diCQA and Coffea arabica green bean by d) $35.431 \mathrm{mg} \mathrm{L}^{-1}$ 5-CQA. 
coffee extracts than in the ground, instant and roasted coffee extracts because of the influence of process technology of green bean. ${ }^{[5,10]}$ In order to determine the difference between each individual CGAs content in coffee samples, univariate test of significance and post-hoc Tukey HSD test were used. Analysis of variance found, in the content of 5-CQA $(F=614.5 ; p=0.00), 3,5-\operatorname{diCQA}(F=222.85$; $p=0.000)$ and 3,4-diCQA and 4,5-diCQA $(F=571.95 ; p=$ $0.000)$, a significant difference between coffee samples, and. C. arabica and C. robusta green beans differ from all other coffee samples ( $p=0.000183)$. Similarly, Tukey's post-hoc test found a significant difference between them and other analysed coffee samples (roasted, ground and instant coffee samples). For the 4-FQA content, analysis of variance did not find the difference among all the analysed coffee samples and Tukey's post-hoc test did not find difference among all the coffee samples. In the content of 3-CQA, 4-CQA and 5-FQA, analysis of variance found that there are some differences between coffee samples which Tukey's post-hoc test confirmed by showing the slight difference among all coffee samples.

\section{Differential Pulse and Square-Wave Voltammetry}

DPV and SWV were methods of choice for characterization of CGAs in coffee extracts because of thespeed, low LOD, low LOQ and a small quantity of the required sample.
Electrochemical properties of coffee extracts were investigated in the $0.1 \mathrm{~mol} \mathrm{~L}^{-1} \mathrm{PBS} \mathrm{pH}$ 7.0. DP voltammograms of analysed coffee extracts are shown in Figure 5. Figure 5 shows two oxidation peaks. First, clearly defined and high peak response occurs in all coffee samples in the potential range between 0.195 to $0.200 \mathrm{~V}$ (on the potentials between the CQAs and diCQAS). Another oxidative peak, which is relatively weakly expressed, appears in the potential range between $0.400 \mathrm{~V}$ to $0.444 \mathrm{~V}$ (in the FQAs oxidation potential range).

In order to confirm the identification of the oxidation peaks, spiking of all coffee extracts was performed by adding the known concentration of each individual CQAs, diCQAs and FQAs (data not shown in this paper). As a result of spiking, a significant increase in the current of the first and the second oxidation peaks was noticed. No change in the oxidation potential with spiking of CQAs and FQAs to coffee extract was observed, but the change of $3 \mathrm{mV}$ to more positive values by the addition of diCQAs was noticed. It could be concluded that the first oxidation peak undoubtedly relates to the oxidation of the CQAs and diCQAs and the second one to the oxidation of FQAs present in the coffee samples. Such identification is supported by HPLC/PDA analysis of coffee (Figure 4) although HPLC analysis showed a relatively small (about $10 \%$ ) FQAs content in coffee extracts (Table 2). Results obtained by DPV are consistent with the literature data. ${ }^{[5,7,10,14,16,25]}$

Table 2. Chlorogenic acids content in some coffee samples obtained using HPLC method. (a)

\begin{tabular}{|c|c|c|c|c|c|c|c|c|c|c|c|}
\hline Sample & 3-CQA & 4-CQA & 5-CQA & $\Sigma \mathrm{CQAs}$ & $\begin{array}{c}\text { 3,4-i 3,5- } \\
\text { dicQAs }\end{array}$ & 4,5-diCQA & $\sum$ diCQAs & 5-FQA & 4-FQA & $\Sigma F Q A s$ & $\begin{array}{l}\Sigma \text { CGAs } \\
\text { (total) }\end{array}$ \\
\hline \multicolumn{12}{|l|}{ Green beans } \\
\hline $\begin{array}{l}\text { C. arabica, Rio } \\
\text { Minas, Brazil }\end{array}$ & $655 \pm 24$ & $909 \pm 43$ & $3933 \pm 94$ & $5497 \pm 162$ & $777 \pm 24$ & $634 \pm 23$ & $1411 \pm 46$ & $305 \pm 16$ & $157 \pm 0$ & $462 \pm 16$ & $7370 \pm 224$ \\
\hline $\begin{array}{l}\text { C. robusta, } \\
\text { Cherry, India }\end{array}$ & $576 \pm 36$ & $801 \pm 67$ & $4130 \pm 264$ & $5507 \pm 367$ & $1477 \pm 84$ & $1047 \pm 34$ & $2524 \pm 118$ & $1046 \pm 39$ & $35 \pm 0$ & $1081 \pm 39$ & $9112 \pm 523$ \\
\hline \multicolumn{12}{|l|}{ Roasted beans } \\
\hline $\begin{array}{l}\text { C. arabica, Rio } \\
\text { Minas, Brazil }\end{array}$ & $445 \pm 11$ & $546 \pm 9$ & $908 \pm 33$ & $1899 \pm 53$ & $174 \pm 1$ & $199 \pm 9$ & $373 \pm 8$ & $197 \pm 2$ & $143 \pm 1$ & $340 \pm 3$ & $2612 \pm 64$ \\
\hline $\begin{array}{l}\text { C. robusta, } \\
\text { Cherry, India }\end{array}$ & $438 \pm 14$ & $529 \pm 15$ & $890 \pm 11$ & $1857 \pm 41$ & $250 \pm 24$ & $244 \pm 7$ & $494 \pm 17$ & $237 \pm 3$ & $237 \pm 6$ & $474 \pm 8$ & $2825 \pm 65$ \\
\hline \multicolumn{12}{|l|}{ Ground coffee } \\
\hline $\begin{array}{c}\text { 1, } 100 \% \\
\text { Minas }\end{array}$ & $669 \pm 20$ & $842 \pm 23$ & $1519 \pm 51$ & $3030 \pm 92$ & $252 \pm 18$ & $260 \pm 7$ & $512 \pm 15$ & $210 \pm 7$ & $179 \pm 4$ & $389 \pm 5$ & $3931 \pm 85$ \\
\hline $\begin{array}{c}2,100 \% \\
\text { arabica }\end{array}$ & $562 \pm 10$ & $703 \pm 12$ & $1308 \pm 35$ & $2573 \pm 55$ & $282 \pm 33$ & $228 \pm 3$ & $510 \pm 33$ & $288 \pm 26$ & $148 \pm 0$ & $436 \pm 47$ & $3519 \pm 117$ \\
\hline \multicolumn{12}{|l|}{ Instant coffee } \\
\hline 1 & $550 \pm 11$ & $638 \pm 25$ & $1025 \pm 5$ & $2213 \pm 31$ & $292 \pm 35$ & $271 \pm 52$ & $563 \pm 87$ & $290 \pm 16$ & $137 \pm 2$ & $427 \pm 96$ & $3203 \pm 22$ \\
\hline 2 & $544 \pm 25$ & $630 \pm 46$ & $1026 \pm 49$ & $2200 \pm 117$ & $290 \pm 36$ & $275 \pm 4$ & $565 \pm 32$ & $302 \pm 19$ & $118 \pm 9$ & $420 \pm 25$ & $3185 \pm 123$ \\
\hline 3 & $578 \pm 18$ & $604 \pm 33$ & $852 \pm 36$ & $2034 \pm 84$ & $293 \pm 73$ & $202 \pm 3$ & $495 \pm 73$ & $596 \pm 3$ & $25 \pm 4$ & $621 \pm 25$ & $3150 \pm 163$ \\
\hline 4 & $622 \pm 23$ & $691 \pm 16$ & $970 \pm 28$ & $2283 \pm 64$ & $314 \pm 27$ & $247 \pm 16$ & $561 \pm 43$ & $420 \pm 15$ & $198 \pm 14$ & $618 \pm 20$ & $3462 \pm 106$ \\
\hline
\end{tabular}


The calibration line of 5-CQA standard was used to calculate total CGAs $\left(I_{p} / \mu \mathrm{A}=0.02216+0.04908 x\right)$ in all coffee extracts (the sum of both anodic oxidation currents). Results are expressed in mg 5-CQAE / $100 \mathrm{~g}$ of coffee. The content of CGAs has a downward trend (as with the SWV method) in green beans, ground coffee, instant coffee to roasted coffee (Table 3 ). The results of the total CQAs content in coffee samples obtained in this study are in agreement with the results of the work of Ziyatdinova et al., ${ }^{[16]}$ who also used the DPV method for determining CGAs in coffee samples, but also with the results of other authors who used the other electrochemical methods or other working electrodes. ${ }^{[11-14,16,17,31]}$

SW voltammograms of the coffee extracts measured in $0.1 \mathrm{~mol} \mathrm{~L}^{-1} \mathrm{PBS}$ pH 7.0 are shown in Figure 6The potential $\left(E_{p}\right)$ of the total current response for the coffee extracts has values between $0.223 \mathrm{~V}$ and $0.229 \mathrm{~V}$, depending on the type of coffee (Figure 6). In one of our earlier studies, it was reported that the oxidation potential of CQAs was $0.223 \mathrm{~V}$ and $0.229 \mathrm{~V}$ for diCQAs. ${ }^{[18]}$ The appearance of SW
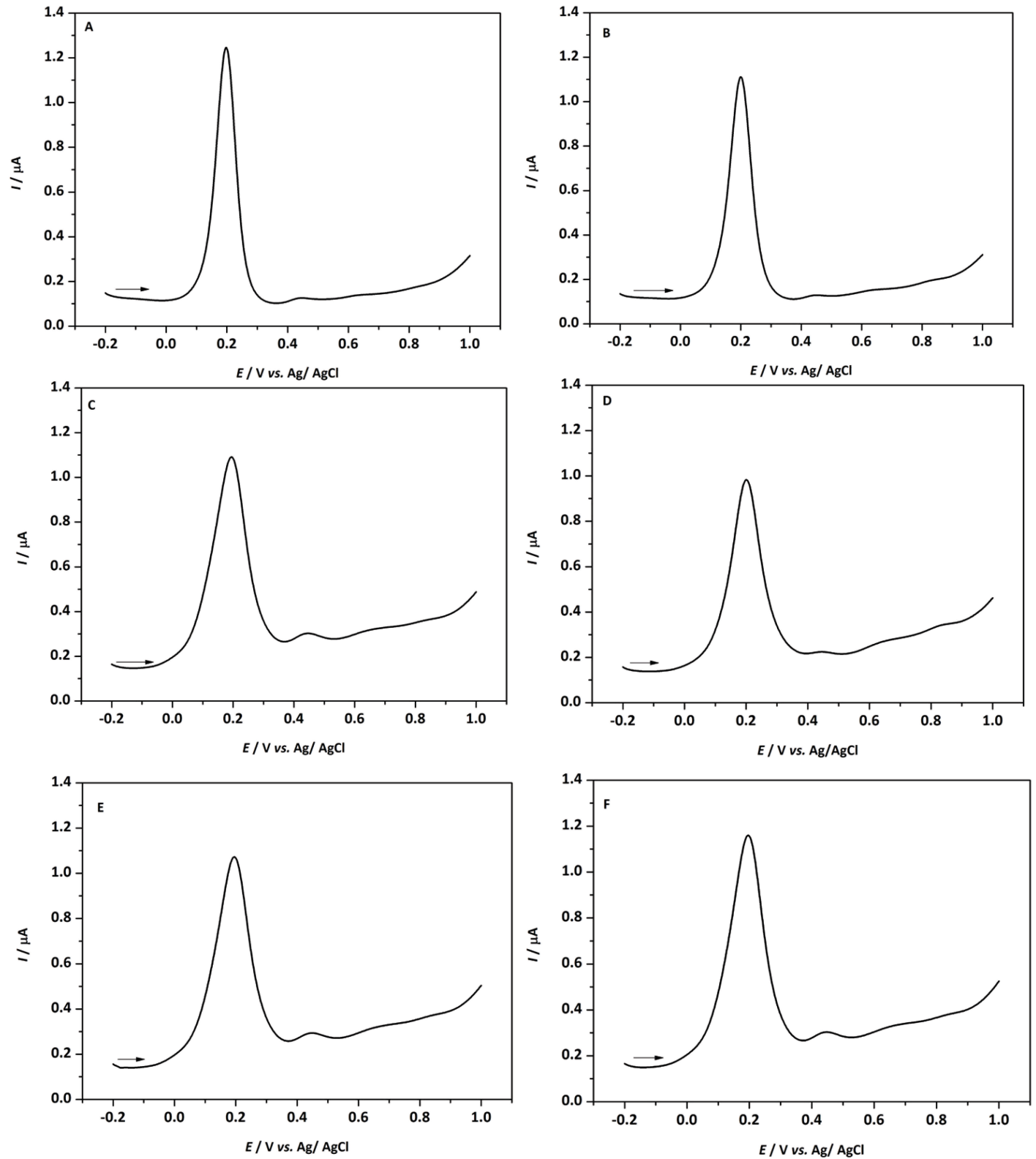

Figure 5. DPV profile of CGAs in ground and instant coffee; $A=$ ground coffee, $100 \%$ minas, $B=$ ground coffee, $100 \%$ arabica, $\mathrm{C}=$ instant coffee $1, \mathrm{D}=$ instant coffee $2, \mathrm{E}=$ instant coffee 3 and $\mathrm{F}=$ instant coffee 4 . 
voltammograms of coffee extracts is identical or very similar to the SW voltammograms obtained in the CQAs and diCQAs solutions. ${ }^{[18]}$ The SW voltammograms of all investigated coffee samples show a clearly expressed oxidation component $\left(l_{f}\right)$ and a reduction component $\left(I_{b}\right)$ of the total current response $(\Delta l)$. From the appearance of SW voltammograms, and the peak potential values (diagnostic criteria for SWV), it could be concluded that the current response obtained in the coffee samples represents the sum of the individual current responses of each individual CQAs and
diCQAs present in all coffee extracts. Since the difference in the oxidation potential between CQAs and diCQAs is very low $(6 \mathrm{mV})$, it was registered as one overall current response (Figure 6). The anode oxidative peak observed on SWV in all investigated coffee samples can be attributed to simultaneous oxidation of each individual CQAs (5-CQA, 4CQA, and 3-CQA) and diCQAs (3,4-diCQAs; 3,5-diCQAs and 4,5-diCQAs), as was reported in our earlier studies. ${ }^{[18,19]}$

According to values of $\Delta E_{p} \approx 26 \mathrm{mV}$ and $l_{f} / I_{b}=-1.7$, the reversible electrochemical oxidation reaction of the
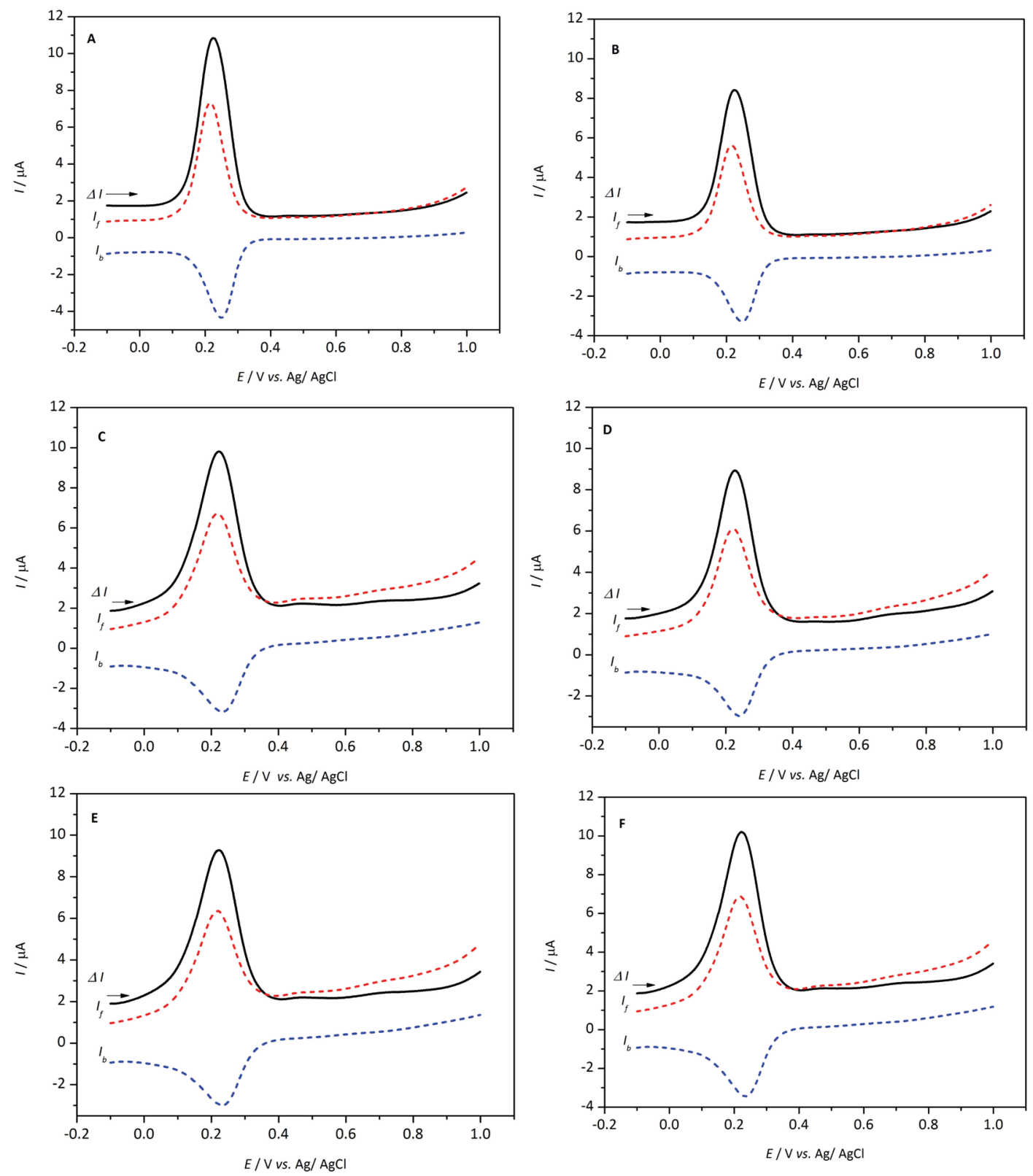

Figure 6. SWV profile of CGAs in ground and instant coffee, $A=$ ground coffee, $100 \%$ minas, B = ground coffee, $100 \%$ arabica, $\mathrm{C}=$ instant coffee $1, \mathrm{D}=$ instant coffee $2, \mathrm{E}=$ instant coffee 3 and $\mathrm{F}=$ instant coffee 4 . 
mixture of each investigated CQAs and diCQAs take place on the GC electrode in coffee extracts during anodic polarization, by the mechanism identical to CQAs and diCQAs. ${ }^{[18,19]}$

The identification of the presence of certain chlorogenic acids (CGAs) was performed using the SWV techniques. The SWV measurements (the appearance of SW peaks and the electrochemical behaviour) confirmed the presence of CQAs and diCQAs in all examined coffee samples. The SWV measurements (the appearance of SW voltammogram and the electrochemical behaviour) confirmed the presence of CQAs and diCQAs in all examined coffee samples. The obtained SWV peaks of FQAs were relatively smaller if compared to those obtained using DPV method, possibly due to very fast SWV scan $\left(100 \mathrm{mV} \mathrm{s}^{-1}\right)$.

In order to confirm the identification of the anodic oxidation peak, the known concentrations of CQAs and diCQAs were spiked to the aqueous coffee extracts. An increase of the current response was noticed on SW voltammograms, but without a change of potentials when the 5-CQA standard was added. After the diCQA solutions were added in the coffee samples, the increase of the current response was noticed together with the small potential displacement of 2-6 mV towards the more positive values, probably due to the strong influence of the adsorption of

Table 3. The CGAs content in the investigated coffee samples. (a)

\begin{tabular}{|c|c|c|c|}
\hline \multirow[b]{2}{*}{ Coffee sample } & $\Sigma C G A s$ (total) & $\Sigma$ CGAs (total) & $\Sigma$ CGAs (total) \\
\hline & $\begin{array}{c}\text { (mg 5-CQAE / } \\
100 \text { g coffee) } \\
\text { DPV }\end{array}$ & $\begin{array}{c}\text { (mg 5-CQAE / } \\
100 \text { g coffee) } \\
\text { SWV }\end{array}$ & $\begin{array}{c}\text { (mg 5-CQAE / } \\
100 \text { g coffee) } \\
\text { HPLC }\end{array}$ \\
\hline \multicolumn{4}{|l|}{ Green beans } \\
\hline $\begin{array}{l}\text { C. arabica, Rio } \\
\text { Minas, Brazil }\end{array}$ & 7451 & 7631 & $7370 \pm 224$ \\
\hline $\begin{array}{l}\text { C. robusta, } \\
\text { Cherry, India }\end{array}$ & 9115 & 9411 & $9112 \pm 523$ \\
\hline \multicolumn{4}{|l|}{ Roasted beans } \\
\hline $\begin{array}{l}\text { C. arabica, Rio } \\
\text { Minas, Brazil }\end{array}$ & 2630 & 2730 & $2612 \pm 64$ \\
\hline $\begin{array}{l}\text { C. robusta, } \\
\text { Cherry, India }\end{array}$ & 2852 & 3186 & $2825 \pm 65$ \\
\hline \multicolumn{4}{|l|}{ Ground coffee } \\
\hline 1, $100 \%$ Minas & 4101 & 4278 & $3931 \pm 85$ \\
\hline 2, $100 \%$ arabica & 3574 & 3914 & $3519 \pm 117$ \\
\hline \multicolumn{4}{|l|}{ Instant coffee } \\
\hline 1 & 3283 & 3566 & $3203 \pm 22$ \\
\hline 2 & 3229 & 3429 & $3185 \pm 123$ \\
\hline 3 & 3203 & 3447 & $3150 \pm 163$ \\
\hline 4 & 3465 & 3796 & $3462 \pm 106$ \\
\hline
\end{tabular}

oxidation products of diCQAs on the surface of the GC electrodes. The measurements carried out by spiking of coffee extracts undoubtedly confirmed that the anodic oxidation current response obtained in the aqueous coffee extract, referring to the electrochemical oxidation of the CQAs and $\operatorname{diCQAs}$, was contained in each of the investigated coffee samples (Figures not shown here).

The total CGAs content in aqueous coffee extracts (CGAs-total) was calculated from the anodic peak current $\left(I_{p}\right)$ of each coffee sample by using a 5-CQA solution calibration curve $\left(I_{p} / \mu \mathrm{A}=0.20326+0.37483 x\right)$ as a standard in the concentration range of $5-50 \mu \mathrm{mol} \mathrm{L}^{-1}$. The total CGAs are expressed as 5-CQA equivalents (mg 5-CQAE / $100 \mathrm{~g}$ of coffee) and are shown in Table 3. It is clear from Table 3 that the total CGAs content is the highest in green beans, followed by ground coffee, instant coffee and the smallest total content of CGAs was measured in the extracts of roasted coffee beans. The content of CGAs in all coffee extract obtained by the SWV method is consistent with the results obtained by the DPV technique (Table 3) and HPLC method (Table 2). Obtained results match with literature data, although the complete agreement is not possible due to different types of coffee samples and different experimental conditions. ${ }^{[5,7,10-14,29,31]}$

\section{CONCLUSION}

This study demonstrates the precise and accurate separation, identification and quantification of CGAs in different coffee samples obtained by HPLC/PDA, DPV and SWV methods. HPLC/PDA method provided the confirmation of both quantitative and qualitative amount of each individual chlorogenic acids. The HPLC/PDA analysis showed that undoubtedly the CQAs, diCQAs and FQAs were present in all investigated coffee extracts based on identification through UV/Vis spectra, retention times, spiking and appearance of HPLC chromatograms. Both applied voltammetric techniques (DPV and SWV) as well as HPLC/PDA method are simple, sensitive and selective methods for characterization of CGAs in coffee samples. The analysed green bean coffee extracts showed the highest content of each individually investigated chlorogenic acids, followed by ground coffee and instant coffee, and at the end, by roasted coffee beans. The correlation between total CGAs content in the coffee samples obtained using both voltammetric methods and chromatographic technique showed excellent agreement. The significance of this study is in the correct and detailed separation, identification and quantification of each individual CQAs, diCQAs and FQAs presented in coffee samples using the HPLC/PDA method. Applied chromatographic and voltammetric methods prove themselves to be very good methods for the characterization of CGAs in coffee samples. 
List of abbreviations

CQA - caffeoylquinic acid

diCQA- dicaffeoylquinic acid

FQA - feruloylquinic acid

CGAs - chlorogenic acids

HPLC/PDA - high performance liquid chromatography /

photo diode array

DPV - differential pulse voltammetry

SWV - square-wave voltammetry

Acknowledgment. Authors wish to express their gratitude to Zdenko Hameršak, PhD, and Irena Dokli, PhD, from Institute Rudjer Bošković, Zagreb, and Anamarija Company d.o.o. Zagreb.

\section{REFERENCES}

[1] I. A. Ludwig, M. N. Clifford, M. E. J. Lean, H. Ashihara, A. Crozier, Food Funct. 2014, 5, 1695.

[2] J. V. Higdon, B. Frei, Crit. Rev. Food Sci. Nutr. 2006, 46, 101.

[3] T. W. M. Crozier, A. Stalmach, M. E. J. Lean, A. Crozier, Food Funct. 2012, 3, 30.

[4] K. L. Johnston, M. N. Clifford, L. M. Morgan, Am. J. Clin. Nutr. 2003, 78, 728.

[5] A. Farah, T. Paulis, L. C. Trugo, P. R. Martin, J. Agric. Food Chem. 2005, 53, 1505.

[6] C. L. Ky, M. Noirot, S. Hamon, J. Agric. Food Chem. 1997, .45, 786.

[7] G. S. Duarte, A. A. Pereira, A. Farah, Food Chem. 2010, 118, 851.

[8] M. Jeszka-Skowron, A. Zgola-Grzeskowiak, Eur. Food Res. Technol. 2015, 240, 19.

[9] D. Perrone, A. Farah, C. M. Donangelo, J. Agric. Food Chem. 2012, 60, 4265.

[10] A. Farah, C. M. Donangelo, Braz. J. Plant Physiol. 2006, 8, 23.

[11] M. L. Carvalho, M. Santhiago, R. A. Peralta, A. Neves, G. A. Micke, I. C. Vieira, Talanta 2008, 77, 394.

[12] S. K. Moccelini, A. Spinelli, I. C. Vieira, Enzyme Microb. Technol. 2008, 43, 381.
[13] S. C. Fernandes, S.K. Moccelini, C. W. Scheeren, P. Migowski, J. Dupont, M. Heller, G. A. Micke, I. Vieira, Talanta 2009, 79, 222.

[14] Y. Yardim, J. Food Sci. 2012, 77, C408.

[15] Y. Yardim, E. Keskin, Z. Sentürk, Talanta 2013, 116, 1010.

[16] G. Ziyatdinova, I. Aytuganova, A. Nizamova, H. Budnikov, Food Anal. Meth. 2013, 6, 1629.

[17] W. J. R. Santos, M. Santhiago, I. V. P. Yoshida, Anal. Chim. Acta 2011, 695, 44.

[18] M. Šeruga, I. Tomac, Int. J. Electrochem. Sci. 2014, 9, 6134.

[19] I. Tomac, M. Šeruga, Int. J. Electrochem. Sci. 2016, 11, 2854.

[20] J. S. Jeon, H. T. Kim, I. H. Jeong, S. R. Hong, M. S. Oh, K. H. Park, J. H. Shim, A. M. A. El-Aty, J. Chromatogr. B 2017, 1064, 115.

[21] I. Dokli, L. Navarini, Z. Hameršak, Tetrahedron: Asymmetry 2013, 24, 785.

[22] C. Delgado-Andrade, J. A. Rufian-Henares, F. J. Morales, J. Agric. Food Chem. 2005, 53, 7832.

[23] L. Jakobek, M. Šeruga, I. Novak, M. MedvidovićKosanović, Dtsch. Lebensm.-Rundsch. 2007, 103, 369.

[24] K. Fujioka, T. Shibamoto, Food Chem. 2008, 106, 217.

[25] C. E. Mills, M. J. Oruna-Concha, D. S. Mottram, G. R. Gibson, J. P. E. Spencer, Food Chem. 2013, 141, 3335.

[26] E. Bajko, M. Kalinowska, P. Borowski, L. Siergiejczyk, W. Lewandowski, LWT- Food Sci. Technol. 2016, 65, 471

[27] J. P. Cornard, C. Lapouge, L. Dangleterre, C. AlletBodelot, J. Phys. Chem. A 2008, 112, 12475.

[28] A. Belay, E. Libnedengel, H. K. Kim, Y. H. Hwang, Luminescence 2016, 31, 118.

[29] J. Tošović, S. Marković, Croat. Chem. Acta 2016, 89, 535.

[30] N. Kuhnert, H. Karaköse, R. Jaiswail in Handbook of Analysis of Active Compounds in Functional Foods (Eds: L. M. L. Nollet, F. Toldra) Boca Raton, CRC Press, Taylor \& Francis Group, LLC, 2012, pp. 461-510.

[31] P. A Kilmartin, C. F. Hsu, Food Chemistry 2003, 82, 501. 